\section{A short term study of the additive effect of timolol and brimonidine on intraocular pressure}

MK Arici, M Sayici, Mi Toker, H Erdoğan and A Topalkara
Abstract

Purpose To evaluate the additive ocular hypotensive effect of the combination of brimonidine and timolol on intraocular pressure (IOP) reduction in patients with glaucoma.

Methods This was a prospective, randomized, double-masked, crossover study in 20 patients with primary open angle glaucoma (POAG) on therapy receiving timolol maleate $0.5 \%$ twice daily, with IOP greater than or equal to $22 \mathrm{mmHg}$ in one eye. The treatment period was 3 weeks and during this period timolol + brimonidine or timolol + placebo were applied topically twice daily and IOP, blood pressure, heart rate and pupil size were measured.

Results Combined therapy (timolol + brimonidine) had clinically significant IOPlowering effect during the treatment period $(P<0.01)$. The mean diurnal IOP was significantly reduced by an average of 5.1-5.9 mmHg (21.2-24.5\%) compared with baseline value. The timolol + placebo combination had no clinically significant IOP-lowering effect $(P>0.05)$. No clinically significant side effects were observed during the treatment of both groups.

Conclusions This study showed that the combination of topically applied

brimonidine and timolol cause a marked and sustained IOP reduction.

Eye (2002) 16, 39-43. DOI: 10.1038/

sj/EYE/6700035

Keywords: glaucoma; timolol; brimonidine

\section{Introduction}

Brimonidine tartrate $0.2 \%$ is an effective alpha $_{2}$ adrenergic agonist, that lowers intraocular pressure (IOP) by decreasing aqueous production and increasing uveoscleral outflow. ${ }^{1,2}$ Brimonidine has been shown to effectively lower IOP in glaucomatous, ocular hypertensive and normotensive eyes. ${ }^{3-5}$

It has been shown that brimonidine was well tolerated, safe and clinically effective in lowering IOP. ${ }^{6}$ However, the cardiopulmonary effects of brimonidine were limited to a slight reduction in systolic blood pressure during recovery from exercise and at $4 \mathrm{~h}$ after instillation. $^{7}$

In many countries, the $\beta$-adrenergic antagonists are often the first monotherapy choice of glaucoma or ocular hypertension therapy. Many patients treated with this single medication required adjunctive therapy to adequately reduce IOP in the long term. Alpha adrenergic agonists, latanoprost, dorzolamide and pilocarpine can be added to this therapy. There was no placebo-controlled study on the brimonidine and timolol maleate combination. For this reason we have performed this clinical placebo-controlled study of the additive effect of brimonidine tartrate $0.2 \%$ and timolol maleate $0.5 \%$ in a short-term period.

Patients and methods

Twenty patients were enrolled into this prospective, randomized, double-masked, crossover study which was conducted from November 1998 to December 2000. The patients who had POAG and uncontrolled IOP (IOP $\geq 22 \mathrm{mmHg}$ ) and were receiving timolol maleate $0.5 \%$ alone were included in this study. One eye of each patient was selected for treatment and in the patients with bilateral glaucoma, the eye with the higher IOP was chosen.
Department of Ophthalmology Cumhuriyet University School of Medicine Sivas, Turkey

Correspondence: MK Arici Cumhuriyet Üniversitesi Tip Fakültesi Göz ABD-58140

Sivas, Turkey

Tel: +90346

2191010/2225

Fax: +90 3462191284

E-mail: kemalarici@

hotmail.com 
All patients met the following criteria: age older than 22 years, a clinical diagnosis of primary open-angle glaucoma, patients already receiving timolol twice daily, corrected visual acuity of $20 / 80$ or better in each eye.

Patients were excluded from the study for any of the following reasons: active ocular infection and ocular disease other than glaucoma (blepharitis or cataract e.t), use of systemic and topical medications except timolol, prior treatment with any ocular surgery or laser therapy, contraindications to the use of alphaadrenoreceptor agonist, female patients who were pregnant, lactating, or unstable cardiopulmonary disease.

The patients were informed about this study and a signed informed consent form was obtained from all patients before study entrance. This was approved by Cumhuriyet University, Faculty of Medicine Ethics Committee. Medical and ocular history were obtained from all patients before starting the study.

Subsequently, all patients underwent slit-lamp biomicroscopy, gonioscopy, fundus examination, visual field examination and IOP measurements. Heart rate, blood pressure and pupil size were also recorded. All IOP measurements were performed using a Goldmann applanation tonometer; with the scale masked for the investigator, the tonometer scale was read by an assistant. Three consecutive readings were taken at each time, and the mean of the three values was used in the statistical analyses. The heart rate and blood pressure were measured in a resting position. Pupil diameter was measured with a millimeter ruler in the same room and under constant illumination while subjects fixed on an object about $6 \mathrm{~m}$ away with the other eye. Throughout the study, patients were monitored for signs and symptoms of adverse effects and at all time points biomicroscopic evaluation was performed.

On day 0 (baseline day), IOP, heart rate, blood pressure and pupil size were measured at $9 \mathrm{am}, 3 \mathrm{pm}$ and $9 \mathrm{pm}$. Baseline values were obtained by calculating the mean of the $9 \mathrm{am}, 3 \mathrm{pm}$ and $9 \mathrm{pm}$ values. After these measurements were obtained, either brimonidine tartrate $0.2 \%$ or placebo were applied twice daily for 3 weeks to the patients receiving timolol maleate $0.5 \%$ twice daily. At the end of first, 2nd and 3rd weeks, IOP, heart rate, blood pressure and pupil size were measured for each day at $9 \mathrm{am}, 3 \mathrm{pm}$, and $9 \mathrm{pm}$. After a wash-out period (4 weeks) during which only timolol was used, patients received timolol plus other test medication for 3 weeks.

Timolol was applied at $7 \mathrm{am}$ and $7 \mathrm{pm}$. Test medications had been applied 5 min after each timolol dose.
Commercially available timolol (Cusimolol, Alcon Cusi, SA, El Masnou, Spain), brimonidine (Alphagan, Allergan Inc, Irvine, CA, USA) and artificial tears (Liquifilm Tears, Allergan) were used. Diurnal IOP, blood pressure and heart rate were defined as the mean value over the day, based on the values obtained at $9 \mathrm{am}, 3 \mathrm{pm}$, and $9 \mathrm{pm}$.

The results are presented as the mean \pm standard deviation. RM-ANOVA (Repeated measurementsanalysis of variance) tests were used for statistical analysis of diurnal IOP, blood pressure and heart rate changes from baseline values. Wilcoxon signed rank test was used for statistical evaluation of differences in pupil size. Mann-Whitney U test was used for statistical analysis between the timolol + brimonidine and timolol + placebo group. Statistical calculations were carried out using the SPSS (9.05 for Windows version) package (SPSS Inc, Chicago, IL, USA). A $P$ value $<0.05$ was considered statistically significant.

\section{Results}

Twenty patients were included in the study, $8(40 \%)$ women and $12(60 \%)$ men with a mean age of $62.2 \pm$ 8.6 years ( $46-72$ years). All patients were white and had POAG. The patients had been treated with timolol for a mean of $9.05 \pm 3.7$ months (range 6-15) prior to the study.

The mean IOP before and after the treatment period is presented in Table 1 for each treatment group. The mean baseline diurnal IOP for patients receiving timolol + brimonidine and timolol + placebo was 24.1 $\pm 3.7 \mathrm{mmHg}$ and $24.3 \pm 5.3 \mathrm{mmHg}$ respectively. The difference between mean baseline IOP for both groups was not statistically significant $(P>0.05)$.

The mean diurnal IOP of 1,2 and 3 weeks was lower in the timolol + brimonidine group than in the timolol + placebo group $(P<0.05)$.

The timolol + brimonidine group showed a statistically significant decrease in IOP at each time period when compared with their baseline values and the timolol + placebo group $(P<0.01)$. In this group, further mean diurnal IOP reductions at the first, second and third week were $5.1 \mathrm{mmHg}(21.2 \%), 5.9$ $\mathrm{mmHg}(24.5 \%), 5.7 \mathrm{mmHg}(23.6 \%)$, respectively $(P<$ 0.01 ). Further IOP reductions at the first, second and third week are given in Table 2 for each time period. The maximum IOP lowering effect was seen on week 2. While maximum (peak) reduction of IOP was seen at $9 \mathrm{am}$, minimum (non-peak) reduction of IOP was seen at $3 \mathrm{pm}$. In the timolol + placebo group there were no significant reductions in IOP at all time periods when compared with their baseline values $(P$ $<0.05)$. 
Table 1 Baseline and after treatment mean intraocular pressure $(\mathrm{mmHg} \pm \mathrm{SD})$

\begin{tabular}{|c|c|c|c|c|c|c|c|c|}
\hline \multirow[t]{2}{*}{ Time } & \multicolumn{4}{|c|}{ Timolol + Brimonidine } & \multicolumn{4}{|c|}{ Timolol + Placebo } \\
\hline & Baseline & 1 week & 2 weeks & 3 weeks & Baseline & 1 week & 2 weeks & 3 weeks \\
\hline $9 \mathrm{am}$ & $24.8 \pm 4.5$ & $18.9 \pm 5.3^{*}$ & $17.5 \pm 4.5^{*}$ & $17.7 \pm 6.2^{*}$ & $25.4 \pm 4.1$ & $24.4 \pm 4.5^{* *}$ & $25.5 \pm 7.8^{* *}$ & $25.1 \pm 6.5^{* *}$ \\
\hline $3 \mathrm{pm}$ & $23.2 \pm 3.6$ & $19.9 \pm 5.9^{*}$ & $18.8 \pm 6.1^{*}$ & $19.1 \pm 5.1^{*}$ & $23.3 \pm 5.4$ & $23.2 \pm 5.3^{* *}$ & $23.8 \pm 4.3^{* *}$ & $23.5 \pm 7.2^{* *}$ \\
\hline $9 \mathrm{pm}$ & $24.3 \pm 5.9$ & $18.2 \pm 3.1^{*}$ & $18.3 \pm 5.4^{*}$ & $18.4 \pm 4.3^{*}$ & $24.2 \pm 5.1$ & $24.1 \pm 3.5^{* *}$ & $23.9 \pm 5.1^{* *}$ & $23.7 \pm 5.4^{* *}$ \\
\hline $\mathrm{MD}$ & $24.1 \pm 3.7$ & $19.0 \pm 5.0^{*}$ & $18.2 \pm 5.3^{*}$ & $18.4 \pm 5.4^{*}$ & $24.3 \pm 5.3$ & $23.9 \pm 3.7^{* *}$ & $24.4 \pm 6.6^{* *}$ & $24.1 \pm 6.8^{* *}$ \\
\hline
\end{tabular}

MD: Mean diurnal IOP.

${ }^{*} P<0.01$ (compared with baseline value).

${ }^{*} P>0.05$ (compared with baseline value).

Table 2 Further IOP reduction at first, second and third weeks for both groups (mmHg)

\begin{tabular}{|c|c|c|c|c|c|c|}
\hline \multirow[t]{2}{*}{ Time } & \multicolumn{3}{|c|}{ Timolol + Brimonidine } & \multicolumn{3}{|c|}{ Timolol + Placebo } \\
\hline & 1 week & 2 weeks & 3 weeks & 1 week & 2 weeks & 3 weeks \\
\hline $9 \mathrm{am}$ & $5.9(23.8 \%)$ & $7.3(29.4 \%)$ & $7.1(28.6 \%)$ & $1.0(3.9 \%)$ & $-0.1(-0.4 \%)$ & $0.3(1.2 \%)$ \\
\hline $3 \mathrm{pm}$ & $3.3(14.2 \%)$ & $4.4(19.0 \%)$ & $4.1(17.7 \%)$ & $0.1(0.4 \%)$ & $-0.5(-2.1 \%)$ & $-0.2(-0.9 \%)$ \\
\hline 9 pm & $6.1(25.1 \%)$ & $6.0(24.7 \%)$ & $5.9(24.3 \%)$ & $0.1(0.4 \%)$ & $0.3(1.2 \%)$ & $0.5(2.1 \%)$ \\
\hline MD & $5.1(21.2 \%)$ & $5.9(24.5 \%)$ & $5.5(23.6 \%)$ & $0.4(1.6 \%)$ & $-0.1(-0.4 \%)$ & $0.2(0.9 \%)$ \\
\hline
\end{tabular}

Mean systolic and diastolic blood pressure, heart rate and pupil size are shown in Table 3 for both groups. In both groups, there were no statistically significant differences in systolic and diastolic blood pressure, heart rate and pupil size $(P>0.05)$. Both medications were well tolerated and there were no adverse effects leading to discontinuation of use.

\section{Discussion}

$\mathrm{Alpha}_{2}$ agonists are a relatively new group of drugs for treatment of glaucoma. Clonidine, apraclonidine and brimonidine are in this group. Brimonidine is the latest agent of this group and is a relatively selective alpha agonist that, because of its different chemical structure, may have theoretical advantages compared with apraclonidine. It was released commercially by Allergan in late 1996 in the USA. Its effects on aqueous dynamics are different from apraclonidine, although both are in the same drug group. Brimonidine tartarate $0.2 \%$ lowers IOP by decreasing aqueous production and additionally increasing uveoscleral outflow. ${ }^{1,2}$

The efficacy and the safety of brimonidine were evaluated in previously reported studies. The brimonidine group had mean IOP lowering ranging from 6.3 to $7.6 \mathrm{mmHg}$. At the 12th hour, the brimonidine group had mean IOP lowering ranging from 3.7 to 5.0 mmHg. ${ }^{8}$ When the efficacy of brimonidine was compared with betaxolol the mean decrease in IOP with brimonidine was $5.5-6.2 \mathrm{mmHg}$ and with betaxolol was $3.5-4.1 \mathrm{mmHg}$. Brimonidine had greater IOP lowering effect than betaxolol at every time point $(P<0.003) .^{5}$

Table 3 Blood pressure ( $\mathrm{mmHg}$ ), heart rate (beats $/ \mathrm{min}$ ) and pupil size $(\mathrm{mm})$ in timolol + brimonidine and timolol + placebo groups

\begin{tabular}{|c|c|c|c|c|}
\hline & \multicolumn{4}{|c|}{ Timolol + Brimonidine group } \\
\hline & Baseline & 1 week & 2 weeks & 3 weeks \\
\hline Systolic blood pressure & $112.0 \pm 11.0$ & $109.0 \pm 11.8$ & $110.4 \pm 12.4$ & $112.6 \pm 11.7$ \\
\hline Diastolic blood pressure & $72.8 \pm 11.1$ & $69.8 \pm 9.9$ & $71.6 \pm 9.3$ & $72.8 \pm 10.7$ \\
\hline Heart rate & $80.3 \pm 4.4$ & $80.1 \pm 3.5$ & $80.5 \pm 3.8$ & $79.7 \pm 3.7$ \\
\hline \multirow[t]{2}{*}{ Pupil size } & $3.6 \pm 0.9$ & $3.4 \pm 0.4$ & $3.5 \pm 0.7$ & $3.3 \pm 0.8$ \\
\hline & \multicolumn{4}{|c|}{ Timolol + Placebo group } \\
\hline Systolic blood pressure & $121.8 \pm 12.2$ & $120.0 \pm 10.7$ & $114.8 \pm 12.8$ & $115.6 \pm 11.7$ \\
\hline Diastolic blood pressure & $74.8 \pm 12.2$ & $70.6 \pm 8.9$ & $72.5 \pm 9.2$ & $71.7 \pm 9.5$ \\
\hline Heart rate & $78.7 \pm 5.7$ & $80.5 \pm 5.8$ & $78.8 \pm 5.6$ & $81.7 \pm 5.7$ \\
\hline Pupil size & $3.5 \pm 0.6$ & $3.3 \pm 0.2$ & $3.6 \pm 0.4$ & $3.4 \pm 0.7$ \\
\hline
\end{tabular}


Melamed et al and LeBlanc compared the long-term safety and ocular hypotensive efficacy of brimonidine with timolol administered twice daily in patients with glaucoma or ocular hypertension. It was shown that both drugs significantly lowered IOP from baseline. ${ }^{9,10}$ Timolol is known to reduce IOP by decreasing the rate of aqueous flow. ${ }^{11,12}$ As brimonidine tartarate $0.2 \%$ was administered twice daily concomitantly with timolol maleate $0.5 \%$, an additive effect on IOP reduction can be expected, because of their different mechanisms in decreasing IOP. This study was conducted to research the additive effect of the combination of brimonidine and timolol. Our study revealed that, twice daily brimonidine causes a significant additive reduction in IOP in POAG patients, where IOP was inadequately controlled by timolol treatment alone. Our results show that further reduction of IOP at the first, second and third week was $5.1 \mathrm{mmHg}(21.2 \%), 5.9 \mathrm{mmHg}(24.5 \%)$ and $5.7 \mathrm{mmHg}(23.6 \%)$, respectively. Maximum additional reduction of IOP was observed in the second week. Peak reduction provided an indication of maximum efficacy of a medication. We determined the peak reduction of IOP was at 9 am and non-peak reduction of IOP was at $3 \mathrm{pm}$. Centofanti et al also evaluated timolol and brimonidine combination on the timolol uncontrolled glaucomatous patients. They showed that further reduction of IOP was $16.1 \%$ and $24.7 \%$ after 1 and 3 months respectively, compared with using timolol alone. ${ }^{13}$ These results supported our findings.

In previous studies, brimonidine was studied as an adjunctive agent for glaucoma. ${ }^{14-17}$ Yüksel et al found that there was a statistically significant IOP decrease with timolol and single drop brimonidine. ${ }^{14}$ Stewart et al also reported similar results. ${ }^{16}$ These results support our study, however, in Yüksel's study, they used only a single dose of brimonidine. Additionally, we received only the patients with uncontrolled IOP by timolol treatment alone. Moreover, brimonidine was welltolerated and reduced IOP in most patients when used as a third-line adjunctive therapy. ${ }^{17}$

Many antiglaucoma medications may cause side effects, for example use of orally administered carbonic anhydrase inhibitors is limited by a high incidence of systemic complaints. ${ }^{18}$ It is possible that $\beta$-blocker therapy when combined with brimonidine would be better tolerated than when combined with either cholinergic agonists or carbonic anhydrase inhibitors.

In clinical studies, it was found that brimonidine caused only minimal mean blood pressure changes compared with timolol. Group changes in systolic and diastolic blood pressure were within $2 \mathrm{mmHg}$ from baseline and were not clinically significant for either group. ${ }^{8,19}$ In other studies, brimonidine and betaxolol 0.25 suspension were compared. Mean changes in systolic and diastolic blood pressure in the brimonidine and betaxolol groups were negligible and not clinically significant. ${ }^{5}$ In the treadmill exercise study with one drop of drug administered to normal volunteers, the cardiovascular effects of brimonidine were limited to a slight suppression of the systolic blood pressure during the recovery period. ${ }^{7}$

In patients receiving brimonidine compared with timolol, no significant effect on mean changes from baseline heart rate were noted. The timolol group had lowered slightly mean heart rate at baseline at each visit. During the 3-month study period when brimonidine and betaxolol 0.25 suspension were compared, no statistically significant differences in mean heart rate were seen between the two treatment groups at any visit. ${ }^{5}$

Like betaxolol and unlike timolol, brimonidine did not depress heart rate in subjects who received one drop of drug before undergoing exercise stress testing. ${ }^{11}$ Heart rate was evaluated at each time point throughout the study. Changes in the mean heart rate and blood pressure were minimal, with no significant changes from the measurements taken at baseline or in the placebo group.

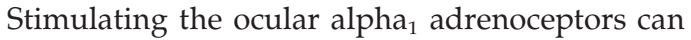
cause mydriasis. Mydriasis is considered as an undesirable side effect of glaucoma therapy because the dilated iris can decrease the angle between the iris and cornea. This can trigger angle-closure glaucoma in certain patients. Mydriasis may cause photosensitivity and blurred vision. In our study we found that brimonidine had no significant effects on pupil size, so we can use this drug on patients with angle closure glaucoma safely.

Our results demonstrate that brimonidine produces a further reduction of IOP when applied to the patients with glaucoma treated with timolol, and that combined therapy would be clinically useful for patients not adequately controlled with $\beta$ adrenergic antagonists alone.

\section{Acknowledgement}

This study not supported by any sponsor.

\section{References}

1 Cambridge D. UK - 14,304, a potent and selective $\alpha$ agonist for the characterization of $\alpha$-adrenoceptor subtypes. Eur J Pharmacol 1981; 72: 413-415.

2 Toris CB, Gleason ML, Camras CB, Yablonski ME. Effects of brimonidine on aqueous humour dynamics in human eye. Arch Ophthalmol 1995; 113: 1154-1157. 
3 Derick RJ, Robin AL, Walters TR et al. Brimonidine tartrate: a one month dose response study. Ophthalmology 1997; 104: 131-136.

4 David R, Walters TR, Sargent JB et al. The safety and efficacy of brimonidine tartrate $0.08 \%, 0.2 \%, 0.35 \%$ and $0.5 \%$ in normotensive subjects. Eur J Ophthalmol 1995; 5 (Suppl 2A): 156 (Abstract).

5 Serle JB and the Brimonidine Study Group III. A comparison of the safety and efficacy of twice-daily brimonidine $0.2 \%$ versus betaxolol $0.25 \%$ in subjects with elevated intraocular pressure. Surv Ophthalmol 1996; 41 (Suppl): 39-47.

6 Schuman JS, Horwitz B, Choplin NT, David R, Albracht $\mathrm{D}$, Chen K. A 1-year study of brimonidine twice daly in glaucoma and ocular hypertension. A controlled, randomized, multicenter clinical trial. Chronic Brimonidine Study Group. Arch Ophthalmol 1997; 117: 417-419.

7 Nordlund JR, Pasquale LR, Robin AL et al. The cardiovascular, pulmonary and ocular hypotensive effects of $0.2 \%$ brimonidine. Arch Ophthalmol 1995; 113: 77-83.

8 Joel SS. Clinical experience with brimonidine $0.2 \%$ and timolol $0.5 \%$ in glaucoma and ocular hypertension. Surv Ophthalmol 1996; 41 (Suppl 1): 27-37.

9 Melamed S, David R. Ongoing clinical assessment of the safety and efficacy of brimonidine compared with timolol: year-three results. Brimonidine Study Group II. Clin Ther 2000; 22: 103-111.

10 LeBlanc RP. Twelve-month results of an ongoing randomized trial comparing brimonidine tartrate $0.2 \%$ and timolol $0.5 \%$ given twice daily in patients with glaucoma or ocular hypertension. Brimonidine Study Group 2. Ophthalmology 1998; 105: 1960-1967.

11 Yablonski ME, Zimmerman TJ, Waltman SR, Becker B. A fluorophotometric study of the effect of topical timolol on aqueous humour dynamics. Exp Eye Res 1978; 27: 11351142.

12 Coakes RL, Brubaker RF. The mechanism of timolol in lowering intraocular pressure in the normal eye. Arch Opthalmol 1978; 96: 2045-2048.

13 Centofanti M, Manni GL, Gregori D, Parisi V, Cocco F, Bucci MG. Brimonidine $0.2 \%$ behaviour on intraocular pressure in timolol-uncontrolled glaucomatous patients. Acta Ophthalmol Scand Suppl 1999; 77: 52

14 Yüksel N, Altintaş O, Karabaş L, Alp B, Çağlar Y. The short-term effect of adding brimonidine $0.2 \%$ to timolol treatment in patients with open-angle glaucoma.

Ophthaomologica 1999; 213: 228-233.

15 Stewart CW, Sharpe ED, Harbin TS, Pastor SA, Day DG, Holmes KT et al. Brimonidine $0.2 \%$ versus dorzolamide $2 \%$ each given three times daily to reduce intraocular pressure. Am J Ophthalmol 2000; 129: 723-727.

16 Stewart WC, Sharpe ED, Day DG, Kolker AE, Konstas AG, Lee WH et al. Comparison of efficacy and safety of latanoprost $0.005 \%$ compared to brimonidine $0.2 \%$ or dorzolamide $2 \%$ when added to a topical beta-adrenergic blocker in patients with primary open-angle glaucoma or ocular hypertension. J Ocul Pharmacol Ther 2000; 16: 251259.

17 Simmons ST, Samuelson TW. Comparison of brimonidine with latanoprost in the adjunctive treatment of glaucoma. Clin Therapeut 2000; 22: 388-399.

18 Hoskins HD Jr, Kass MA. Becker-Shaffer's Diagnosis and Therapy of the Glaucoma, 6th edn. CV Mosby: St Louis, 1989, Chs 23, 26.

19 Schuman JS. Effects of systemic beta-blocker therapy on the efficacy and safety of topical brimonidine and timolol. Brimonidine Study Groups 1 and 2. Ophthalmology 2000; 107: 1171-117. 